Article

\title{
Energy Storage Coordination in Energy Internet Based on Multi-Agent Particle Swarm Optimization
}

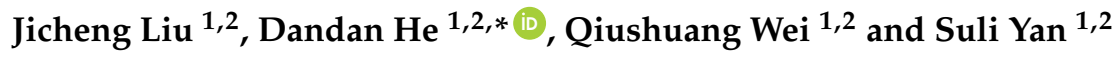 \\ 1 School of Economics and Management, North China Electric Power University, Hui Long Guan, Chang Ping \\ District, Beijing 102206, China; ljc29@163.com (J.L.); blbqhjj@163.com (Q.W.); yabc66@163.com (S.Y.) \\ 2 Beijing Key Laboratory of New Energy and Low-Carbon Development, North China Electric Power \\ University, Hui Long Guan, Chang Ping District, Beijing 102206, China \\ * Correspondence: 1152206090@ncepu.edu.cn; Tel.: +86-188-0110-8577
}

Received: 10 August 2018; Accepted: 29 August 2018; Published: 1 September 2018

Featured Application: The results of this study can be used in the design of coordination and configuration of multiple energy storages in energy Internet or in a hybrid renewable energy system. The proposed algorithm can be applied to solve the problem of single objective optimization or multi-objective optimization which should be converted to a single one first.

\begin{abstract}
With the rapid development of energy Internet (EI), energy storage (ES), which is the key technology of EI, has attracted widespread attention. EI is composed of multiple energy networks that provide energy support for each other, so it has a great demand for diverse energy storages (ESs). All of this may result in energy redundancy throughout the whole EI system. Hence, coordinating ESs among various energy networks is of great importance. First of all, we put forward the necessity and principles of energy storage coordination (ESC) in EI. Then, the ESC model is constructed with the aim of economic efficiency (EE) and energy utilization efficiency (EUE) respectively. Finally, a multi-agent particle swarm optimization (MAPSO) algorithm is proposed to solve this problem. The calculation results are compared with that of PSO, and results show that MAPSO has good convergence and computational accuracy. In addition, the simulation results prove that EE plays the most important role when coordinating various ESs in EI, and an ES configuration with the multi-objective optimization of EE and EUE is concluded at last.
\end{abstract}

Keywords: energy Internet (EI); energy storage (ES); coordination; multi-agent Particle Swarm Optimization (MAPSO)

\section{Introduction}

As the situations of climate change and energy crises become more severe, renewable energies will gradually replace fossil energies, leading to fundamental changes in the structure of the energy system. The popularity of the Internet and the rapid development of information technology has brought new opportunities for the revolution of the traditional energy system, thus enabling multiple energy sources to develop coordinately. Therefore, the concept of energy Internet (EI) came into being.

EI has just been proposed, and there is no unified understanding or definition of its structure and composition. How to build an EI system is still in dispute [1-4]. In general, the main features of EI are: through mutual conversion and complementation of energies such as electricity, heat and mechanical energy, the interconnection of the power grid, heating network, gas network, oil network, water network etc. are integrated together, which can realize information sharing of various energy systems [5,6]. 
In the background of EI, energy storage (ES) will become an important basic support and key technology for EI, and it plays a key role in the transferring, matching and optimization of energies $[7,8]$. EI consists of all kinds of energy networks, in which energy subnets can provide energy support for each other, which leads to great requirement for capacity and types of energy storages (ESs), so that the redundancy of ESs will occur in the entire EI system. The coordination of various ESs helps to reduce the total demand for stored energy and improve economic efficiency (EE). Therefore, according to the overall demand of EI, it is necessary to coordinate and cooperate with diverse types of ESs with the aim of EE and energy utilization efficiency (EUE).

ES plays a significant role in EI, which attracts research interest [9]. Previous literature has mostly concentrated on the application of ES in EI and the coordination of ESs or ES with renewable energies. A table to classify the literature has been created, as shown in Table A1 in the Appendix A.

\section{(1) Application of ES in EI}

Several functions of ES in EI were summarized [10]. Besides peak load shifting, which were mainly discussed in the existing literature, there were some other functions, including coupling and decoupling among multi-energy systems, full utilization of renewable energies, new energy management and transaction model etc. The role of ES in EI was divided into six types: time transfer of energy, space transfer of energy, reserve of energy, fast throughput, storing small sums of energies gradually and using all in one time and storing all energies in one time and using gradually. Others focused on the application of certain ES technologies in EI [11,12].

Baronti et al. [13] discussed innovative solutions for the design and management of ES systems, and their integration into e-transportation and smart grids according to 24 research papers. For the better development of smart grids and bridging the gap between supply and demand for renewable energy generation, Mumtaz et al. [14] provided an overview of energy storage systems (ESSs) and introduced technologies and working principles and the current and future applications of ESSs. Aktas et al. [15] proposed a new smart energy management algorithm for a hybrid ES system, including battery and ultra-capacitor ES units of smart grids and analyzed several different operation cases in this system, providing the test results in eight different operation modes. Rahbar et al. [16] put forward an algorithm that jointly optimized energy charged/discharged to a shared ES system to solve the energy management problem of multiple users with renewable energy sources and a single shared ES system in smart grids. Sutanto [17] presented the benefits of ES systems and the role of power electronics in micro-grid systems. Faccio et al. [18] found that the integration of solar energy, wind energy and battery is the most frequent configuration, and most techniques applied to configure the components of hybrid renewable energy systems were outlined.

\section{(2) Coordination of ESs or ES with renewable energies}

As for cooperation of various ESs, Mokhtari et al. [19] put forward a distributed control method for the coordination of multiple ES units to avoid violation of voltage and thermal constraints. In order to solve over-voltage problems with multiple suitably sized ES systems in low-voltage distribution networks, an approach to coordinate multiple battery ES systems was proposed, and the performance of coordinated control and non-coordinated control was compared [20]. A coordination approach of ES systems was presented for network operation including normal, over-voltage, and under-voltage control modes [21]. Considering that ES can not only contribute to their owners' inherent activities, but also to a more flexible and efficient distribution network operation, Miranda et al. [22] constructed a model for the coordination of distributed ES systems in distribution networks and applied mixed-integer linear programming to maximize the technical and economic value of the distributed storage. Rostami et al. [23] put forward a scalable wide area control scheme applying distributed model predictive control so as to enhance the angle stability of power systems after large disturbances. With the optimization of EE and EUE, Zhu et al. [24] applied particle swarm optimization (PSO) to solve the problem of energy storage coordination (ESC) in EI. 
On the other hand, some other scholars studied the coordination of ES and renewable energies. Early in 1992, Lee et al. [25] established multi-pass dynamic programming to solve the problem of short-term hydrothermal coordination considering pumped storage and battery ES systems aiming at economic benefits. Bortolini et al. [26] presented a model from the technical and economic perspective for the design of a grid-connected photovoltaic plant with a battery ES system aiming at minimizing the levelized cost of electricity. In order to specify the photovoltaic plant rated power, the system capacity of the battery ES and the technical configuration (which can reduce the levelized cost of electricity and carbon footprint of energy), Bortolini et al. [27] put forward a bi-objective design model for off-grid photovoltaic battery ES-diesel generator hybrid energy system. After that, a dynamic cost model for the energy mix planning and the electrical grid management was proposed by Bortolini et al. [28]. Barros et al. [29] presented an approach to coordinate independent non-dispatchable generators and ES systems aiming to maximize the production of the generators so as to maximize their income. A control algorithm considering both ES system capacity and grid reliability was designed to mitigate wind power fluctuations [30]. In order to minimize the total cost of the hybrid renewable energy system consisting of a wind farm, photovoltaic plant, fuel cell and battery storage, a three design criteria optimal method was proposed [31]. Khosravi et al. [32] conducted the energy, exergy and economic analysis for a system composed of off-grid photovoltaic, wind power and fuel cells.

As for the planning of ESs, most studies concentrated on the integration of ES and renewable energies [33-36], ES and flexible demand [37,38], or the cooperation of a variety of ESs in a certain power system [19,22], and few researchers studied the coordination of multiple ESs in EI [24]. Therefore, in the context of EI, this paper optimizes energy storage coordination (ESC) from the perspective of EE and EUE.

To handle these issues, multi-agent particle swarm optimization (MAPSO) is proposed in this paper. Particle swarm optimization (PSO) is derived from the study of bird predator behavior. Essentially, it belongs to an iterative random search algorithm, which can find the global optimal solution with high probability and fast computational efficiency [39]. A multi-agent system (MAS) is a network structure composed of multiple agents dispersing physically or logically, and they complete complex control tasks or problems through negotiation and coordination [40,41]. MAPSO applies the topology of PSO to MAS architecture, in which each agent is equivalent to one particle in PSO. In addition, each agent competes and cooperates with its neighbor's agent, and it can converge faster and more accurately to global optimal solutions combining evolutionary mechanisms and particle update rules of PSO.

Previous scholars integrated PSO with MAS [42,43]. In addition, MAPSO was mostly applied to power systems. Zhao et al. [44] used MAPSO to solve the problem of reactive power optimization. On the basis of combining multi agent technology, Xiao et al. [45] put forward MAPSO to handle a distribution network reconfiguration problem. Kumar et al. [46] presented a MAPSO based on hybrid PSO technology applied to the economic load dispatch which is a non-linear constrained optimization problem. Moreover, Shunmugalatha et al. [47] applied MAPSO for the optimization of maximizing loadability limit of power systems.

In summary, most scholars studied the coordination of ESs or ES with renewable energies from a technical point of view, and there is little literature that takes ESC as the topic in EI. Moreover, EI involves a variety of energy sources and energy conversion, and the structure and mode of operations are more complex and diverse. Hence, both the capacity and type of ESs are in great demand, and diverse functions of EI can be achieved with abundant uses of ESs. Therefore, according to the overall demand of an EI system, three scenarios with the optimization of EE and EUE (uniting EE and EUE) are demonstrated in this study. MAPSO is applied here to handle this optimization problem.

The remainder of this paper is organized as follows. Section 2 analyzes the necessity and principles of ESC in EI. In Section 3, the mathematical formulation of ESC is constructed. In Section 4, PSO, MAS and MAPSO are described in detail. Section 5 presents a numerical example and a comparison with 
PSO to verify the feasibility and superiority of the proposed algorithm is given. Finally, Section 6 summarizes the main conclusions and research limitations.

\section{Necessity and Principles of ESC}

\subsection{Performance of Different ES Technologies}

The technical development level of ESs is different, including the following parameters: power grade, continuous discharge time, time of stored energy, cost, lifetime and conversion efficiency. The main technical parameters of ESs are shown in Table 1.

Table 1. Technical parameters of ESs [48-50].

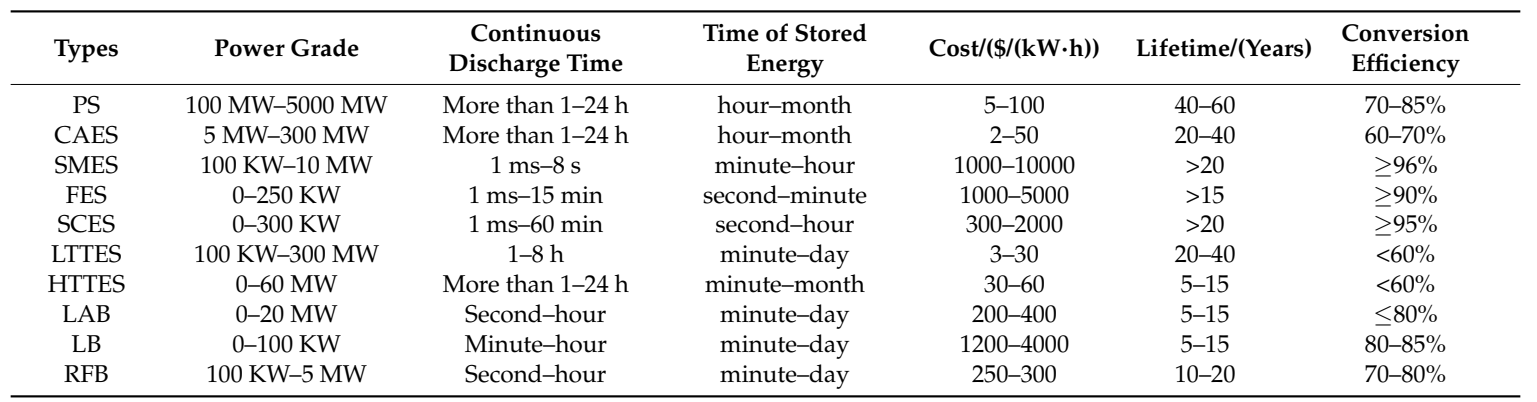

PS: Pumped Storage; CAES: Compressed Air Energy Storage; SMES: Superconducting Magnetic Energy Storage; FES: Flywheel Energy Storage; SCES: Super Capacitor Energy Storage; LTTES: Low Temperature Thermal Energy Storage; HTTES: High Temperature Thermal Energy Storage; LAB: Lead-Acid Battery; LB: Lithium Battery; RFB: Redox Flow Battery.

\subsection{Necessity}

The core feature of EI is transformation and interconnection of multiple energy sources, and its energy network has expanded from power grids to diversified networks including transportation networks, oil networks, gas networks, water networks and so on. As a result, a variety of ES methods such as hydrogen storage, thermal storage and coal storage etc. have emerged. Various ESs of EI are shown in Figure 1. Electricity, coal, oil, gas, etc. can be converted to each other, and the unused energy is transmitted through different energy networks and then stored. Finally, user demand data, energy supply data and ES data are analyzed by an ES system and different energies are distributed rationally.

In order to ensure the stable and efficient operation of EI, various forms of ESs should be matched and coordinated properly, i.e., ESC. The necessity of ESC is analyzed from five aspects.

(1) Reduce ES redundancy of EI system

Different forms of ESs have their corresponding and changing needs in ESC. Nevertheless, the maximum demand for each kind of ES does not occur at the same time. Thus, converting a small-demand ES to a large-demand one can effectively utilize the remaining energy of the ES with small demand, which helps to reduce ES redundancy.

(2) Make full use of the remaining capacity of large ES equipment

For some large-scale ES equipment, such as pumped storage (PS), compressed air energy storage (CAES), etc., their capacity is large, and the power grade is high, so the remaining capacity can be applied to other places while meeting the needs of EI. Therefore, in the information sharing environment, ESC takes full advantage of the remaining capacity of large ES equipment.

(3) Improve EE of EI system

Transportation costs caused by ES can be reduced through different energy conversion. Moreover, storage costs generated by energy redundancy can be reduced owing to alternative energy as well. In addition, ESC can decrease the cost of equipment renewal brought by energy storage. 


\section{(4) Improve EUE of EI system}

Through conversion and substitution of energy, all kinds of ESs can be reasonably collocated. It is preferred to make full use of ES with higher conversion efficiency. At the same time, the storage time of some ESs with a higher self-discharge rate can be reduced, thereby reducing energy attenuation so as to improve EUE.

\section{(5) Guarantee security of EI system}

All kinds of ESs are mutually reserved and supported in safety. If one ES fails and cannot provide the required energy, other ESs will be activated by means of energy conversion or direct substitution to ensure the security and stability of an EI system.

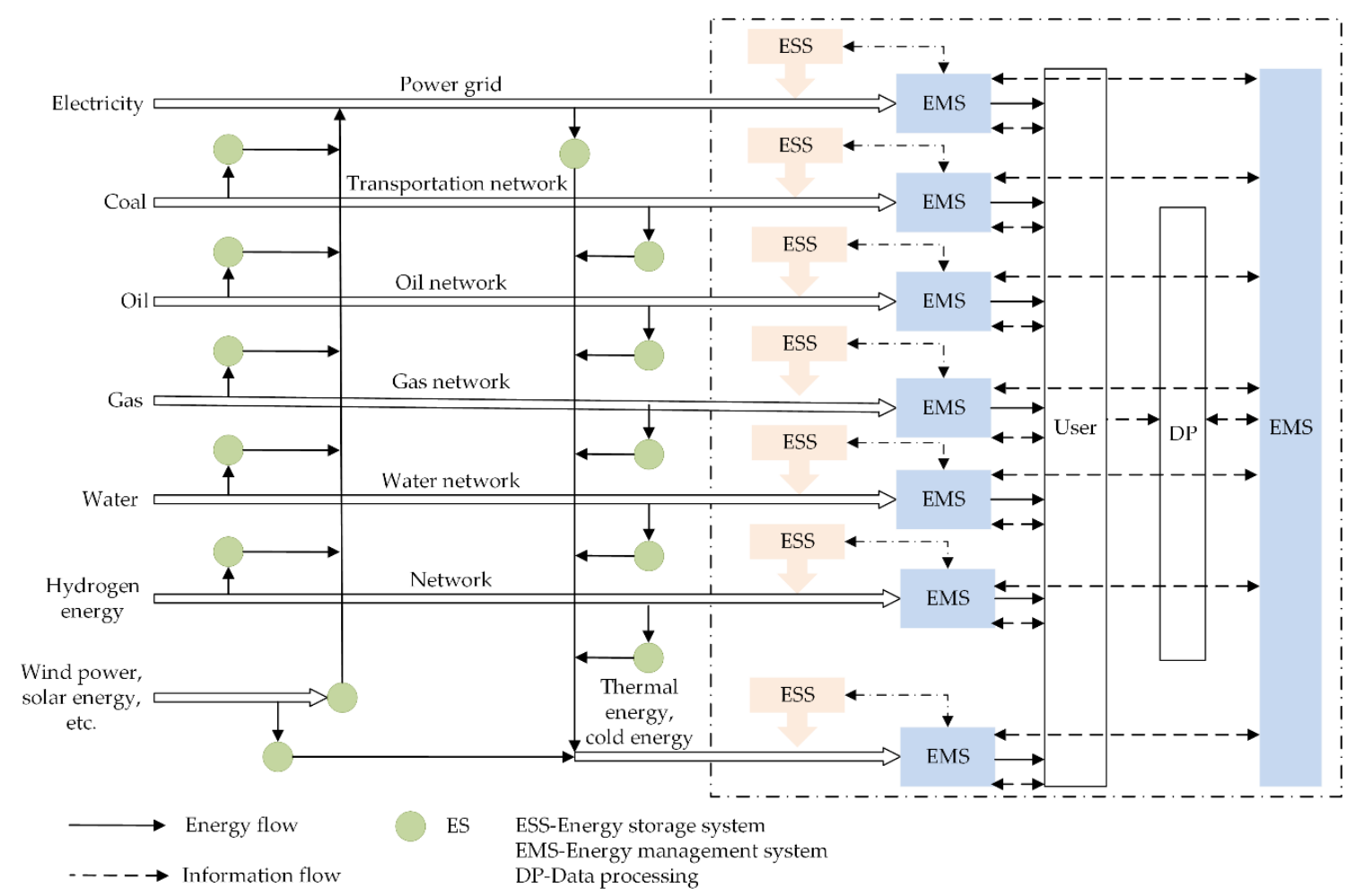

Figure 1. Various energy storages (ESs) of energy Internet (EI).

\subsection{Principles}

Five principles of ESC are proposed in this work based on the above mentioned five aspects of necessity and other previous studies related to coordination of ESs or ES with renewable energies [24,51-55].

(1) Meet the total demand of stored energy

When allocating the capacity of ES, it is a prerequisite to meet the total demand of stored energy. Only in this way can the balance of supply and demand be reached, and the stable operation of the EI system be guaranteed.

(2) Meet power grade demand

The requirements for power grade are diverse due to the degree of economic development. For instance, industrial cities need a higher power grade, while areas with backward development and low per capita distribution density have fewer power grade requirements. Accordingly, the ESC should meet the demand of power grade. 
(3) Guarantee the reasonable storage and release speed

Different places have different performance requirements for ES. For example, some places with a high penetration rate of renewable energies are prone to power fluctuation, which requires ESs with fast storage and release speed. As a result, it is necessary to take the speed of ES release into account while coordinating ESs.

(4) Ensure the highest EUE

EUE consists of storage efficiency and conversion efficiency. The energy attenuation degree is diverse in different types of ESs, and the ES with less loss should be selected to improve storage efficiency. The same kind of energy could be provided by different energy sources, resulting in the existence of conversion efficiency. The formula of conversion efficiency is shown in Equation (1).

$$
\rho=\frac{E_{r}}{E_{S}}
$$

where, $E_{r}, E_{s}$ represent released energy and stored energy respectively.

(5) Ensure the optimal EE of EI system

The EE of ES is affected by a large number of factors [56], including lifetime, cost and so on. The cost of ES should be the lowest and the EE should be the best.

All types of ESs work together in EI to ensure the system operates stably, efficiently, and economically. According to the characteristics of different ESs, as well as the demand situation, a reasonable arrangement of various ESs can meet the requirements of EI [57]. However, the configuration of ESs in EI involves a large number of factors, leading to the complexity of deciding optimization factors and formulating problems. Consequently, on the basis of the necessity and principles of ESC proposed in this Section, the objective functions and constraint conditions of ESC optimization are put forward below.

\section{Problem Formulation}

\subsection{Objective Functions}

Suppose the total required energy of a certain EI system provided by ESs is $E_{\text {total }}$, and the energy here refers to converted energy, which is different from stored energy, and the following is the same. The demand of fixed basic energy is $E_{\text {basic }}$. There are $y$ kinds of ES forms in total, and the basic requirement for each one is $e_{i}(i=1,2,3, \ldots, y)$. However, the number of ESs in this area is $l$, and the stored energy of each ES is $x_{i}(i=1,2,3, \ldots, l, l \leq y)$. In addition, the required energy for real-time is $E_{\text {real }}$, and that of non-real-time is $E_{\text {non-real }}$. Next, the existing ES methods are coordinated based on optimization of EE and EUE.

\section{(1) Economic efficiency (EE)}

When it comes to ES for power systems, the total cost is composed of the cost of a central storage system, the cost of a power transformation system, and the cost of a charge-discharge control system [58]. As for a certain ES, such as liquid air ES, its total cost consists of the cost for the liquefaction unit, cryogenic tanks and the discharging unit [59]. However, various forms of ESs are discussed in this paper, and the calculation and component of its total cost are relatively complicated. Therefore, considering the universality of ES cost and for the convenience of calculation, the total cost here is made of variable cost, not including fix/investment costs. Various ESs have corresponding different costs. As shown in Table 1, the cost of PS and CAES is relatively low, and the technology is much more mature. As a result, they should be selected first as far as possible. The total cost is calculated as follows:

$$
C=\sum x_{i} f\left(C_{\text {imin }}, C_{\text {imax }}\right)
$$


where $C$ represents the total cost; $C_{i \min }$ and $C_{i \max }$ are the minimum and maximum values of the $i$ th ES cost respectively; $f$ function is the selection of cost according to actual situation.

(2) Energy utilization efficiency (EUE)

In this paper, EUE is characterized by the stored energy consumed under the same converted energy. To meet the energy demand of this EI system, the total stored energy required of all ESs is shown in Equation (3).

$$
E=\sum_{i=1}^{n} x_{i}
$$

where $E$ stands for the total stored energy of all ESs in EI system.

\subsection{Constraint Conditions}

Constraints of ESC include energy constraints, equipment and material constraints, total energy constraints, basic performance constraints, and real-time constraints. The meaning and mathematical expression of the specific constraints are as follows.

(1) Energy constraint

Any form of ES access will change the energy distribution of EI, but the overall energy conservation should be always met, which means that Equation (4) ought to be satisfied.

$$
E_{R E}-E_{S E}=E_{C E}
$$

where $E_{R E}$ represents the energy released by various energy networks, $E_{S E}$ is the energy stored by ESs and $E_{C E}$ is the consumed energy.

(2) Equipment and material constraint

Due to raw material and equipment hardware, the capacity of stored energy can be limited. Suppose the maximum storage capacity of each ES is $X_{\text {imax }}$, and the constraint is expressed in Equation (5).

$$
x_{i} \leq X_{\text {imax }}
$$

(3) Total energy constraint

In order to ensure the stable operation of EI, the stored energy should meet the overall demand, which means the capacity of total stored energy should be no less than the total amount of energy required, which is shown in Equation (6).

$$
\sum_{i=1}^{n} x_{i} \cdot \rho_{i} \geq E_{\text {total }}
$$

where, $\rho_{i}$ represents energy conversion efficiency of the $i$ th ES.

(4) Basic performance constraint

The basic requirements of EI for ES ought to be guaranteed for system operation, as shown in Equation (7).

$$
x_{i} \cdot \rho_{i} \geq e_{i}(i \in m)
$$

(5) Real-time constraint 
For some large disturbances and transient faults, high real-time ES (RTES) forms are usually in need, including superconducting magnetic energy storage (SMES), flywheel energy storage (FES), super capacitor energy storage (SCES) etc. The constraint is presented in Equation (8).

$$
\sum\left(x_{i} \cdot \rho_{i}-e_{i}\right) \geq E_{\text {real }}\left(x_{i} \in \mathrm{RTES}\right)
$$

In order to solve this optimization problem, MAPSO can quickly and accurately converge to the optimal solutions proposed in this study. The source, analysis and concrete steps of MAPSO are described and analyzed in detail in Section 4.

\section{Multi-Agent Particle Swarm Optimization (MAPSO) Approach}

\subsection{Particle Swarm Optimization (PSO)}

PSO was developed by Eberhart et al. [39,60], which was proposed through the inspiration of birds searching for food. Each particle adjusts its position on the basis of its own experience and information sharing by its neighbors. In this algorithm, the velocity vector of each particle is determined by the direction and rate of flight, and the position of the particle is used to represent the optimized problem.

Suppose a group composed of $z$ particles exists in a d-dimensional search space. Then, the position information and the speed information of the $j$ th particle can be expressed by Equations (9) and (10).

$$
\begin{aligned}
& Q_{j}=\left(q_{j 1}, q_{j 2}, \ldots, q_{j d}\right)^{\prime}, j=1,2,3, \ldots, z \\
& V_{j}=\left(v_{j 1}, v_{j 2}, \ldots, v_{j d}\right)^{\prime}, j=1,2,3, \ldots, z
\end{aligned}
$$

The velocity information and position information of the $j$ th particle are updated according to Equations (11) and (12).

$$
\begin{gathered}
v_{t+1}=w \cdot v_{t}+c_{1} \cdot r_{1} \cdot\left(p_{\text {best }}-q_{t}\right)+c_{2} \cdot r_{2} \cdot\left(g_{\text {best }}-q_{t}\right) \\
q_{t+1}=q_{t}+v_{t+1}
\end{gathered}
$$

where $t$ is the iterations, $v_{t}$ stands for the velocity at the $t$ th iteration, $q_{t}$ represents the position at the $t$ th iteration, $w$ is inertia weight, $c_{1}, c_{2}$ are acceleration constants, and $r_{1}, r_{2}$ are random values in the range $[0,1]$. $p_{\text {best }}$ and $g_{\text {best }}$ represent the best previous position of a particle, and index of the best particle among all the particles in this group respectively.

\subsection{Agent and Multi-Agent System (MAS)}

An agent is a physical or virtual entity that accomplishes one or more tasks with the ability of perception, communication and problem solving. Additionally, an agent essentially has the following typical characteristics $[61,62]$.

\section{(1) Perception}

Agents can feel the stimulation of environment, and are completely dependent on their own ability to adjust the behavior without the assistance of others.

(2) Reactivity

An agent can not only feel the changes of the external environment, but also respond to them with different environmental information.

\section{(3) Initiative}

An agent is not simply controlled by the external environment, but can take the initiative to complete a task according to its own actions. 


\section{(4) Communication}

An agent communicates with other agents to enhance its efficiency, which is crucial to the expansibility of itself.

\section{(5) Evolvability}

In other words, evolvability means the learning ability. An agent has certain intelligence and will improve learning ability as actions accumulate, thus solving problems better.

A single agent has a limited ability to solve problems, and it seems to be powerless when encountering huge and complex problems. Accordingly, it is necessary for multiple agents to collaborate to solve problems mutually. Thus, MAS comes into being. MAS is a network structure composed of loosely coupled and coarse-grained agents which are physically or logically dispersed. They accomplish complex control tasks or solve complicated problems through negotiation and cooperation. Generally speaking, a MAS system usually contains the following four elements:

(1) meaning and purpose of each agent

(2) the definition of global environment

(3) the definition of local environment

(4) the behavioral rules that govern the interaction between an agent and its environment.

\subsection{MAPSO}

MAPSO is a new algorithm combining PSO and MAS [63,64]. First of all, determining the structure suitable for MAS so as to confirm the domain of an agent is carried out. Each agent not only competes and cooperates with its neighbors, but also takes advantage of the evolution mechanisms of PSO, which speeds up the information transfer process $[65,66]$. Thus, MAPSO converges faster and more accurately to global optimal solution.

(1) Meaning and purpose of each agent

In MAPSO, each agent $\alpha$ is equivalent to a particle in PSO. The particle has an optimized objective function value which is called the fitness value. The fitness function with the best EE and maximum EUE as the optimization goal is represented by Equations (13) and (14). In other words, the fitness values of agent $\alpha_{1}$ and agent $\alpha_{2}$ are expressed as Equations (13) and (14).

$$
\begin{aligned}
& f\left(\alpha_{1}\right)=C \\
& f\left(\alpha_{2}\right)=E
\end{aligned}
$$

The purpose of agent $\alpha_{1}$ is to minimize its fitness value as long as the constraints are met. On the contrary, the goal of agent $\alpha_{2}$ is to maximize the fitness value.

\section{(2) Global environment of MAPSO}

For the definition of global environment, this paper adopts a simple lattice-like structure, as shown in Figure 2. In Figure 2, each circle represents an agent which is the same as a particle in PSO. The coordinates $(a, b)$ in this circle represent the specific location of an agent in the global environment, and the coordinates have a one-to-one correspondence with each agent. In addition, every agent consists of two pieces of data, namely the speed and location of the particle in PSO. Furthermore, $a \times b$ is the total grid number of this global environment, and the relationship between $a, b$ and the number of particles for PSO $z$ is $z=a \times b$. 


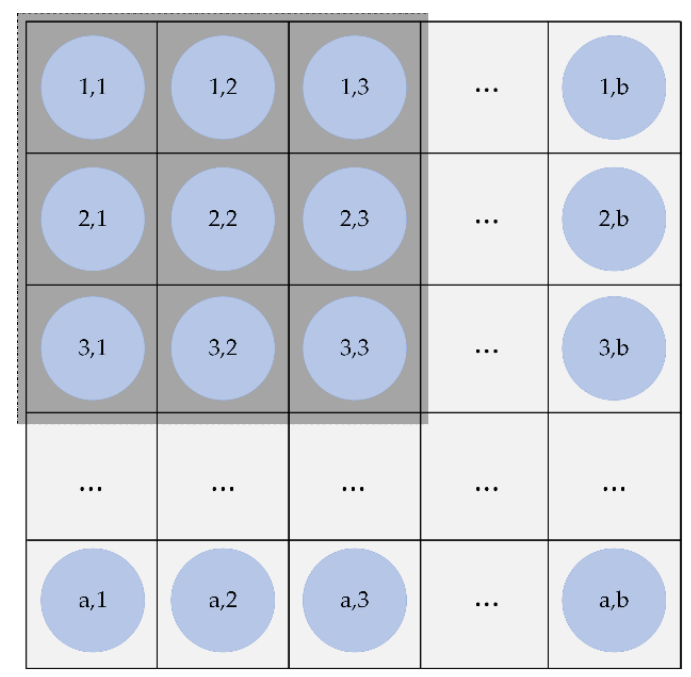

Figure 2. Structure of global environment.

\section{(3) Local environment of MAPSO}

In order to realize communication among particles and obtain the next behavioral strategy, the local environment needs to be defined. Then, each agent will communicate and interact with its neighboring particles in the predefined local environment. Assume $A_{m, n}$ represents the agent with position $(m, n)$, and $m=1,2,3, \ldots, a ; n=1,2,3, \ldots, b,(a, b$ are the global environment boundaries of MAPSO). The local environment $N_{m, n}$ of $A_{m, n}$ is defined as Equation (15).

$$
N_{m, n}=\left\{A_{m, n 1}, A_{m, n 2}, A_{m 1, n}, A_{m 1, n 1}, A_{m 1, n 2}, A_{m 2, n}, A_{m 2, n 1}, A_{m 2, n 2}\right\}
$$

where $m_{1}=\left\{\begin{array}{c}m-1, m \neq 1 \\ a, m=1\end{array} ; n_{1}=\left\{\begin{array}{c}n-1, n \neq 1 \\ b, n=1\end{array} ; m_{2}=\left\{\begin{array}{c}m+1, m \neq a \\ 1, m=a\end{array} ; n_{2}=\right.\right.\right.$ $\left\{\begin{array}{c}n+1, n \neq b \\ 1, n=b\end{array}\right.$.

According to the above definition, as shown in Figure 2, there are several local environments in the global environment. The shade of Figure 2 is the local environment of an agent with coordinates $(2,2)$ and the eight particles around it are the neighbors used to obtain environmental information.

(4) Behavioral strategy of each agent

The agent competes and cooperates with its neighbors. Take the EE of ESC as an example, assuming the position of agent $A_{m, n}$ in the solution space is $A_{m, n}=\left(\alpha_{1}, \alpha_{2}, \ldots, \alpha_{n}\right)$ and $M_{m, n}$ is the agent with the minimum fitness value among eight neighbors of $A_{m, n}$. If $A_{m, n}$ satisfies Equation (16), the position of agent $A_{m, n}$ remains unchanged, otherwise changing according to Equation (17) [48].

$$
\begin{gathered}
f\left(A_{m, n}\right) \leq f\left(M_{m, n}\right) \\
A_{m, n}^{\prime}=M_{m, n}+\operatorname{rand}(-1,1) \cdot\left(A_{m, n}-M_{m, n}\right)
\end{gathered}
$$

where $\operatorname{rand}(-1,1)$ is a random number in the range $[-1,1]$.

As can be seen from Equation (16), $A_{m, n}$ not only retains its original useful information, but also fully absorbs the information of neighbor $M_{m, n}$ and further reduces its fitness value.

\section{(5) Implementation of MAPSO}

Through the introduction to MAPSO, we can see that the combination of MA and PSO provides a more effective method for solving problems. The concrete steps of the MAPSO algorithm are as follows: 
Step 1: $\quad$ Define the global environment $a \times b$.

Step 2: Define the solution space, the maximum number of iterations, the inertia weights $w$, the acceleration constants $c_{1}$ and $c_{2}$. Specify the lower and upper boundaries of all the variables.

Step 3: Initialize the location and speed of an agent in the solution space.

Step 4: Calculate the location coordinates of each agent's neighbor according to Equation (15).

Step 5: Update the time counter.

Step 6: Calculate the fitness value of each agent respectively based on Equations (2) and (3). At the same time, find the initial individual optimal fitness value and the initial global optimal fitness value.

Step 7: Perform the neighborhood competition and cooperation operation of each agent on the basis of Equations (16) and (17). Suppose there is an agent $A_{m, n}$ and $M_{m, n}$ is the agent with the minimum fitness value among eight neighbors of $A_{m, n}$. If $A_{m, n}$ and $M_{m, n}$ satisfy Equation (16), the position of $A_{m, n}$ remains unchanged, otherwise changing according to Equation (17).

Step 8: $\quad$ Update the position and speed of each agent according to Equations (11) and (12).

Step 9: Calculate the fitness value of each agent and then update the individual optimal fitness value and the global optimal fitness value.

Step 10: Determine whether the termination conditions are satisfied. If one of the stopping criteria is not satisfied, then go to Step 5. Otherwise, go to Step 11.

Step 11: Output the agent with the optimal fitness value in the last generation.

\section{Case Study}

Take an area of A, which is one of the EI Demonstration Projects in China, as an example for simulation. This project contains a hybrid system of off-grid photovoltaic power (PV)-wind power plant (WPP)-conventional gas turbine (CGT). In order to reduce the instability and randomness caused by wind power and photovoltaic power, it is necessary to introduce ES in the EI Demonstration Projects. However, the decision makers consider this demonstration project not only including electricity, but also containing heat, gas and other energy sources that supply energies mutually. Therefore, energy redundancy may exist here after adopting ES. Hence, theoretical exploration and simulation on ESC are carried out according to the actual situation of Area A to solve the issues mentioned above.

\subsection{Basic Data}

First of all, a field investigation on energy sources and energy utilization of area A was conducted to obtain material data.

Secondly, 14 experts (three professors of economic and management from universities, eight technical managers from ES, PV, WPP, CGT, and three from electricity retailers) were invited to analyze and classify the collected data. Combining the experts' opinions and the decision makers' thinking, the parameters of this EI Demonstration Project are set as follows: the total required energy provided by ESs $E_{\text {total }}$ is $3000 \mathrm{MW} \cdot \mathrm{h}$, the fixed basic energy demand $E_{\text {basic }}$ is $1500 \mathrm{MW} \cdot \mathrm{h}$, the real-time ES $E_{\text {real }}$ is $600 \mathrm{MW} \cdot \mathrm{h}$, and the non-real-time ES $E_{\text {non-real }}$ is $900 \mathrm{MW} \cdot \mathrm{h}$.

Thirdly, the types of ESs are chosen from the perspective of cost, conversion efficiency, real-time processing and technological maturity, as shown in Table 2. We can see from Table 2 that both redox flow battery (RFB) and lead acid battery (LAB) accord with the factors of quick real-time processing and high degree of technological maturity. Unfortunately, the cost of RFB could be much higher than $\mathrm{LAB}$ for the reason that when activated carbon is added to the negative electrode of LAB, its cost will be decreased and the lifetime and performance will be improved. Thus, the eight types of PS, low temperature thermal energy storage (LTTES), LAB, SCES, high temperature thermal energy storage (HTTES), CAES, SMES and FES are selected for Area A. 
Table 2. The chosen ES types from Table 1.

\begin{tabular}{ll}
\hline \multicolumn{1}{c}{ Factors } & \multicolumn{1}{c}{ Types of ESs } \\
\hline Low cost & PS, LTTES, CAES, HTTES \\
High conversion efficiency & SMES, FES, SCES \\
Quick real-time processing & LAB, SCES, SMES, FES, RFB \\
High degree of technological maturity & PS, LAB, RFB \\
\hline
\end{tabular}

Finally, the cost, maximum storage capacity $X_{\text {imax }}$ and basic required energy of each ES $e_{i}$ are decided considering the experts' advice, the technical parameters of ESs in Section 2 cited from references [48-50], and the actual situation of Area A. As for conversion efficiency $\rho_{i}$, the critical values of each ES are selected. These parameters are shown in Table 3.

Table 3. Parameters of selected ESs.

\begin{tabular}{cccccc}
\hline No. & Type & Cost $/(\mathbf{\$} / \mathbf{k W} \cdot \mathbf{h}))$ & $\boldsymbol{\rho}_{\boldsymbol{i}} /(\mathbf{\%})$ & $\boldsymbol{X}_{\boldsymbol{i m a x}} /(\mathbf{M W} \cdot \mathbf{h})$ & $\boldsymbol{e}_{\boldsymbol{i}} /(\mathbf{M W} \cdot \mathbf{h})$ \\
\hline 1 & PS & 50 & 85 & 1000 & 700 \\
2 & LTTES & 15 & 60 & 600 & 300 \\
3 & LAB & 300 & 80 & 600 & 300 \\
4 & SCES & 1000 & 95 & 800 & 200 \\
5 & HTTES & 45 & 60 & 200 & 0 \\
6 & CAES & 25 & 70 & 500 & 0 \\
7 & SMES & 5000 & 96 & 400 & 0 \\
8 & FES & 3000 & 90 & 500 & 0 \\
\hline
\end{tabular}

\subsection{Example Results}

The proposed objective functions in Section 3.1 belong to a single objective optimization which cannot provide a final balance between the configurations of EE and EUE. Therefore, it is necessary to combine EE and EUE together. Hence, the three scenarios of EE, EUE, and the combination of EE and EUE are discussed in this paper separately.

The MATLAB software is applied to solve the optimization problems under these three simulation scenarios. The strategy of ESC is determined by comparison of the optimization results.

\subsubsection{Scenario 1: Economic Efficiency (EE)}

ES in EI is in great demand, but its cost is generally high. Thus, reducing cost becomes key while ES technology remains at the present level. Therefore, based on the goal of improving EE, PSO and MAPSO are adopted to optimize the system under the constraint conditions of Section 3.2.

The population size of MAPSO and PSO is usually determined according to the complexity of problems. The population size of the two algorithms is set as 16 , comprehensively considering the balance between optimization efficiency and optimization results. The size of the global environment is $8^{*} 8$. The maximum iterations are set as 100 . In order to prevent PSO from falling into local optimal solution and improving search ability, this paper applies the linear decreasing inertia weight [60]. The settings of linear weight and acceleration constants are cited from reference [67]. The parameters of PSO and MAPSO are presented in Table 4. 
Table 4. Parameters of particle swarm optimization (PSO) and multi-agent particle swarm optimization (MAPSO).

\begin{tabular}{cccccccc}
\hline Algorithm & Population Size & Iterations & UBIW & LBIW & $c_{\mathbf{1}}$ & $\boldsymbol{c}_{\mathbf{2}}$ & Size of Global Environment \\
\hline PSO & 16 & 50 & 0.9 & 0.2 & 2.0 & 2.0 & \\
MAPSO & 16 & 50 & 0.9 & 0.2 & 2.0 & 2.0 & $8^{*} 8$ \\
\hline
\end{tabular}

UBIW: Upper bounds of inertia weight; LBIW: Lower bounds of inertia weight.

The CPU time required for solving this optimization problem with a Dell Inspiron 7447 series laptop powered by a Inter Core i7-4720HQ processor and 8 GB of RAM is computed 20 times and the average time is $0.056915 \mathrm{~s}$ of MAPSO and $0.026558 \mathrm{~s}$ of PSO. Obviously, the solving time of MAPSO, which is acceptable, is longer than that of PSO. On the other hand, the decision makers are inclined to obtain the optimal results of ESC, thus the optimization results of the two algorithms are discussed below.

The convergence comparison between PSO and MAPSO is shown in Figure 3. At the same time, the comparison of computing results is shown in Table 5 as well.

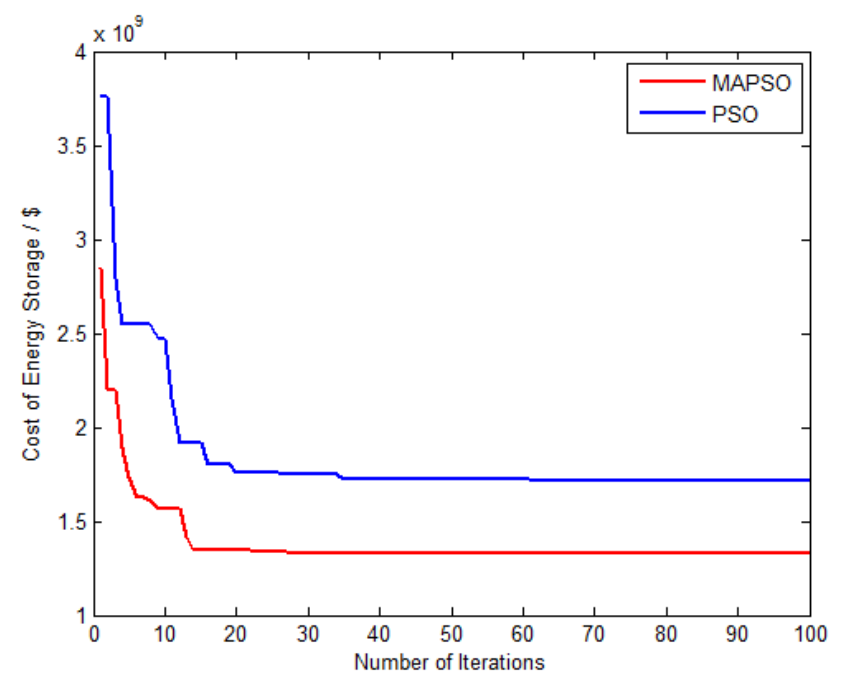

Figure 3. Comparison of convergence with EE objective.

Table 5. Comparison of results with EE objective.

\begin{tabular}{cccc}
\hline Algorithm & $\boldsymbol{C}_{\text {min }} / \mathbf{\$}$ & $\boldsymbol{C}_{\text {mean }} / \mathbf{\$}$ & $\boldsymbol{C}_{\text {max }} / \mathbf{\$}$ \\
\hline PSO & $1.7181 \times 10^{9}$ & $1.8475 \times 10^{9}$ & $3.7571 \times 10^{9}$ \\
MAPSO & $1.3272 \times 10^{9}$ & $1.3911 \times 10^{9}$ & $2.8443 \times 10^{9}$ \\
\hline
\end{tabular}

From Figure 3, we can see that PSO reaches the optimal solution after running about 60 times, while MAPSO descends quickly in the first few generations and reaches the optimal solution after about 30 iterations, which shows the effectiveness and superiority of the algorithm's optimization mechanism. Moreover, as can be seen from Table 5, the minimum, mean and maximum cost of MAPSO is lower than PSO. In summary, the MAPSO algorithm shows better convergence and computational accuracy. Though the processing time of MAPSO is longer than PSO, MAPSO is a valid algorithm in terms of computing results.

\subsubsection{Scenario 2: Energy Utilization Efficiency (EUE)}

Due to the high cost of ES, it is necessary to improve the EUE of ES equipment. This section aims to maximize EUE and optimize it using PSO and MAPSO respectively. Similarly, the linear 
decreasing inertia weight is chosen here, where the parameters of PSO and MAPSO are the same as Section 5.2.1. However, the maximum iterations are changed to 50 on the basis of the tested computing results. The CPU time for solving this issue is calculated 20 times as well using the identical laptop in Section 5.2.1. The average solving time of MAPSO is $0.046338 \mathrm{~s}$ and $0.026641 \mathrm{~s}$ of PSO.

The convergence comparison of PSO and MAPSO with the target of EUE is shown in Figure 4, and the result comparison is presented in Table 6.

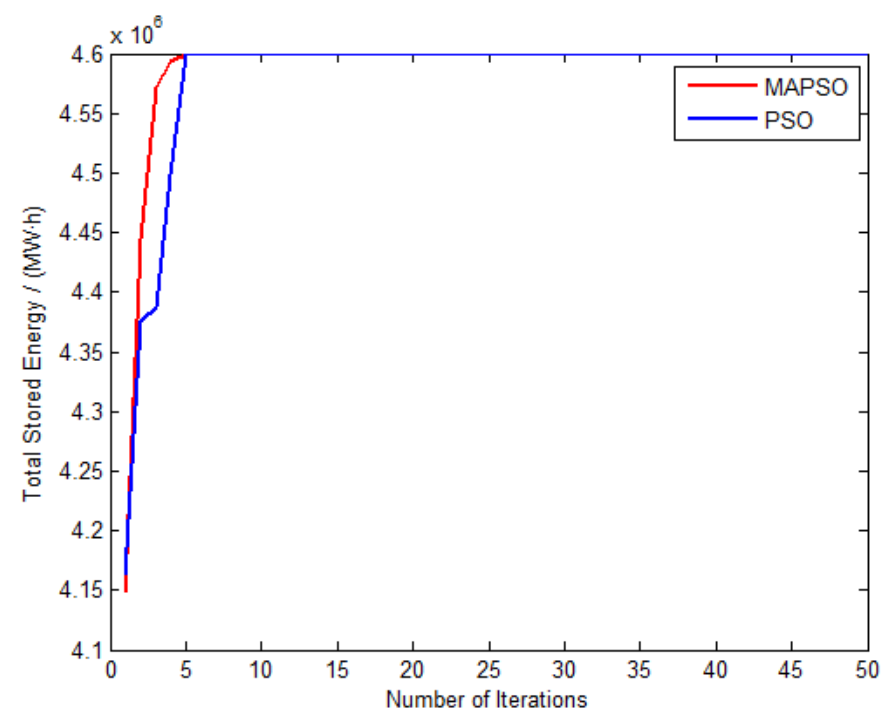

Figure 4. Comparison of convergence with EUE objective.

Table 6. Comparison of results with EUE objective.

\begin{tabular}{cccc}
\hline Algorithm & $E_{\text {min }} /(\mathbf{M W} \cdot \mathbf{h})$ & $E_{\text {mean }} /(\mathbf{M W} \cdot \mathbf{h})$ & $E_{\text {max }} /(\mathbf{M W} \cdot \mathbf{h})$ \\
\hline PSO & $4.1618 \times 10^{6}$ & $4.5899 \times 10^{6}$ & $4.6000 \times 10^{6}$ \\
MAPSO & $4.1481 \times 10^{6}$ & $4.5871 \times 10^{6}$ & $4.6000 \times 10^{6}$ \\
\hline
\end{tabular}

It is known from Figure 4 that MAPSO reaches the optimal solution in about 5 steps, and PSO runs in approximately 5 steps at the same time. From Table 6, the minimum, mean energy capacity of PSO is a little larger than that of MAPSO, while the maximum value obtained by the two algorithms is $4.6000 \times 10^{6} \mathrm{MW} \cdot \mathrm{h}$. As far as the results of Figure 4 and Table 6 are concerned, the advantages of MAPSO are not so obvious. This is because the objective function of EUE is relatively simple, and the superiorities of MAPSO are not well reflected.

\subsubsection{Scenario 3: Uniting EE and EUE}

The proposed optimization model in this scenario combined the objective functions of EE and EUE, which belong to a multi-objective optimization. There are two main strategies for this problem: the direct solution path and the indirect solution path. On the one hand, the direct solution path can search for the optimal solution from a global scope, but the coding is too complicated. On the other hand, the indirect solution path is to assign weight coefficients to each objective function and weight the multi-objective model to a single one. In general, the weights are usually determined by the decision makers according to their subjective experience. This method takes full advantage of the knowledge of decision makers, but it is also subjective. However, this way is easier to get an optimal solution compared with the direct path. Furthermore, the proposed MAPSO is suitable for single objective optimization. Based on the above, we chose the indirect solution path to handle this issue, and how to change the multi-objective functions into a single one is presented below. 
The optimization direction and dimension of the objective function is in difference, so an appropriate treatment is necessary to solve this problem. Set $\vartheta_{c}$ and $\vartheta_{e}$. as weight coefficients of objective function $C$ and $E$, and the united objective function is $\gamma$. The normalized and dimensionless process of the objective function values is expressed in Equation (19) [68].

$$
\gamma=\min \left\{\vartheta_{c} \cdot \frac{C-C^{\min }}{C^{\max }-C^{\min }}+\vartheta_{e} \cdot \frac{E^{\max }-E}{E^{\max }-E^{\min }}\right\}
$$

where $\vartheta_{c}+\vartheta_{e}=1$.

The optimization results of MAPSO and PSO are shown in Figure 5, along with the weight changes between 0.1 and 0.9 of objective function $C$. We know that the cases of EE and EUE belong to the special situations when the weight coefficients of $C$ are 1 and 0 , which are not discussed here. It can be found from Figure 6 that PSO has great volatility when the weight coefficient of $C$ is in the range of 0.2 and 0.5 . When the weight coefficient is between 0.5 and 0.9 , both PSO and MAPSO show a steady upward trend. Therefore, in conjunction with expert opinion, the average of 0.5 and 0.9 is taken as the weight coefficient of $C$ here. Obviously, the weight coefficient of $E$ is 0.3 .

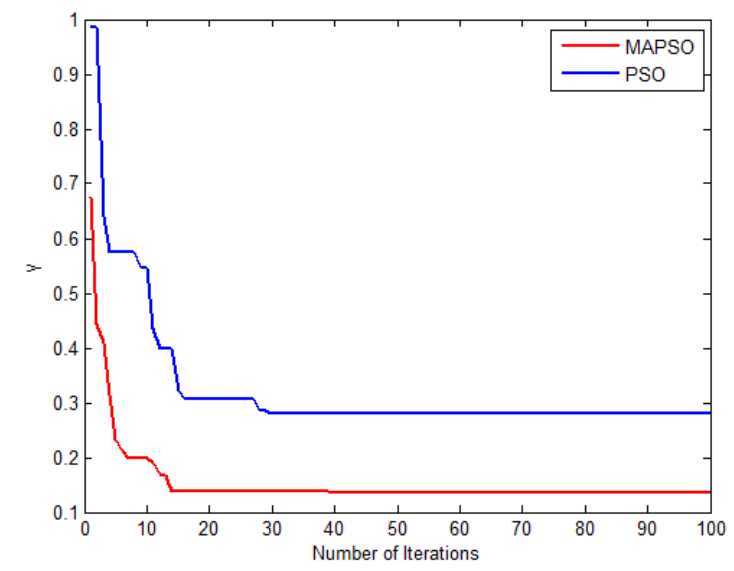

(a)

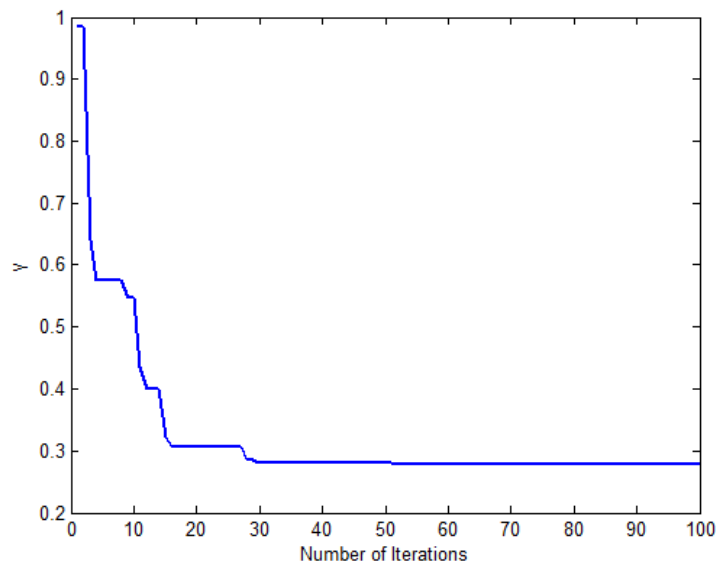

(b)

Figure 5. Convergence comparison of $\gamma$ of PSO and MAPSO (a) and convergence diagram of PSO (b).

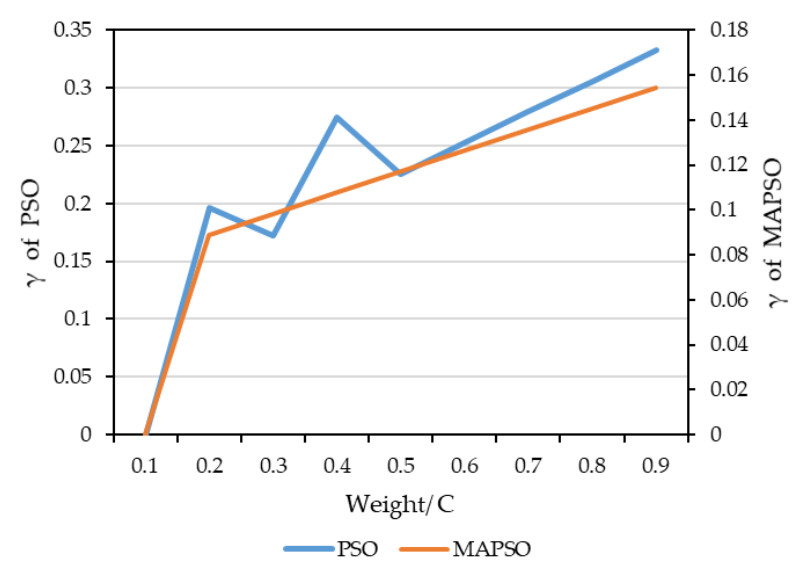

Figure 6. $\gamma$ of PSO and MAPSO under different $\vartheta_{c}$ between 0.1-0.9.

Under these circumstances, the multi-objective optimization is carried out. The settings of the basic parameters and the laptop used are consistent with those in Section 5.2.1. The average solving time for computing PSO and MAPSO 20 times is $0.160904 \mathrm{~s}$ and $0.081907 \mathrm{~s}$, respectively. Similarly, 
the convergence comparison of these two methods and the optimization results are shown in Figure 6 and Table 7.

Table 7. Comparison of results with objective function $\gamma$.

\begin{tabular}{cccc}
\hline Algorithm & $\gamma_{\min }$ & $\gamma_{\text {mean }}$ & $\gamma_{\max }$ \\
\hline PSO & 0.27917 & 0.32659 & 0.98439 \\
MAPSO & 0.13562 & 0.15468 & 0.67486 \\
\hline
\end{tabular}

As shown in a, MAPSO runs about 40 times to achieve the optimal solution, and PSO operates about 50 times, which declines with a tiny step after the 30th iteration as shown in Figure $5 \mathrm{~b}$. Compared with PSO, the minimum, mean and maximum values of $\gamma$ with MAPSO are smaller, which is presented in Table 7. Additionally, the computing time of MAPSO is shorter than that of PSO. All of the results prove the effectiveness and feasibility of the proposed MAPSO.

\subsection{Results Analysis}

We can see from the above results, the convergence and computational accuracy of MAPSO are better than PSO. Thus, ES configuration obtained by MAPSO is discussed below, which is shown in Table 8.

Table 8. Optimal allocation scheme of ESs.

\begin{tabular}{|c|c|c|c|c|c|c|c|c|c|c|}
\hline \multirow{2}{*}{ Object } & \multicolumn{8}{|c|}{ Stored Energy of Each ES/(MW·h) } & \multirow{2}{*}{ Total Cost $/ \$$} & \multirow{2}{*}{$\begin{array}{c}\text { Total Stored } \\
\text { Energy/(MW·h) }\end{array}$} \\
\hline & 1 & 2 & 3 & 4 & 5 & 6 & 7 & 8 & & \\
\hline $\mathrm{EE}$ & 1000 & 600 & 600 & 800 & 200 & 500 & 0 & 88.9 & $1.3272 \times 10^{9}$ & 3788.9 \\
\hline EUE & 1000 & 600 & 600 & 800 & 200 & 500 & 400 & 500 & $4.5605 \times 10^{9}$ & 4600 \\
\hline EE and EUE & 1000 & 502 & 600 & 800 & 200 & 500 & 69.8 & 131.1 & $1.8013 \times 10^{9}$ & 3802.9 \\
\hline
\end{tabular}

The following conclusions can be drawn from Table 8 .

(1) The energy capacity with the objective of EE is $811.1 \mathrm{MW} \cdot \mathrm{h}$ less than that of EUE, while the cost difference is $3.2333 \times 10^{9} \$$. When the capacity of total stored energy increases by $\frac{4600-3788.9}{3788.9}=$ $21.4073 \%$, the cost will raise correspondingly by $\frac{4.5605 \times 10^{9}-1.3272 \times 10^{9}}{1.3272 \times 10^{9}}=243.6181 \%$. The results indicate that under the current ES technology level, if the capacity of stored energy is still increasing, a large cost will need to be paid after it reaches a certain degree. Consequently, it is suggested that decision makers give priority to EE when coordinating various ESs.

(2) Compared with the results of EE, both the cost and the capacity of stored energy will increase with the implementation of multi-objective optimization. However, the cost will rise by $\frac{1.8013 \times 10^{9}-1.3272 \times 10^{9}}{1.3272 \times 10^{9}}=35.7218 \%$ while the capacity increases by only $\frac{3802.9-3788.9}{3788.9}=0.3695 \%$. Both of the two conclusions perform alike, which indicates that decision makers should attach great importance to EE. However, if the diversity of ES is a must, the multi-objective optimization of EE and EUE is the best choice and the capacity of PS, LTTES, LAB, SCES, HTTES, CAES, SMES and FES can be configured as $1000 \mathrm{MW} \cdot \mathrm{h}, 502 \mathrm{MW} \cdot \mathrm{h}, 600 \mathrm{MW} \cdot \mathrm{h}, 800 \mathrm{MW} \cdot \mathrm{h}, 200 \mathrm{MW} \cdot \mathrm{h}$, $500 \mathrm{MW} \cdot \mathrm{h}, 69.8 \mathrm{MW} \cdot \mathrm{h}$, and 131.1 MW·h, respectively. 


\section{Conclusions}

EI has diverse needs for various ES types. Under the certain principle of coordination and optimization, rational allocation of multiple ESs according to features of ESs can not only meet the requirements of EI, but also achieve the purpose of improving EE and EUE. Thus, this paper firstly points out the necessity of ESC. Then, the principles of ESC are presented. Finally, a simulation is carried out applying PSO and MAPSO. The main conclusions of this study are as follows.

(1) The 5 principles when coordinating ESs are summarized: meet the total demand of stored energy; meet the power grade demand; guarantee the reasonable storage and release speed; ensure the highest EUE; ensure the optimal EE of the EI system.

(2) MAPSO combines the competition and cooperation strategy of MAS and the update mechanism of PSO. It overcomes the shortcoming of PSO, improves the ability of global optimization, and has higher computing precision and robustness.

(3) At the current level of ES technology, the pursuit of maximum EUE will cost far more than the benefit of EE. The suggestion that implementing ESC with the goal of EE is put forward.

(4) When considering both EE and EUE, the capacity of PS, LTTES, LAB, SCES, HTTES, CAES, SMES and FES can be configured as $1000 \mathrm{MW} \cdot \mathrm{h}, 502 \mathrm{MW} \cdot \mathrm{h}, 600 \mathrm{MW} \cdot \mathrm{h}, 800 \mathrm{MW} \cdot \mathrm{h}, 200 \mathrm{MW} \cdot \mathrm{h}$, $500 \mathrm{MW} \cdot \mathrm{h}, 69.8 \mathrm{MW} \cdot \mathrm{h}$, and $131.1 \mathrm{MW} \cdot \mathrm{h}$, respectively. The cost will be $1.8013 \times 10^{9} \$$ and the capacity of total stored energy will reach $3802.9 \mathrm{MW} \cdot \mathrm{h}$.

However, there are some limitations in this study. First of all, only eight kinds of ES forms are selected for simulation, while in fact there are many kinds of ES in EI systems. The total cost of ES is more complicated, while this paper only takes the variable cost into account. Reasonable decisions can be made based on actual situations using the model proposed here. Eventually, factors such as capacity configuration and demand response are not considered when designing ESC. Therefore, research can be conducted in the future to deal with these issues.

Author Contributions: Data curation, J.L. and D.H.; Formal analysis, J.L. and D.H.; Funding acquisition, J.L.; Methodology, D.H.; Writing—original draft, D.H.; Writing—review \& editing, D.H., Q.W. and S.Y.

Funding: This research was funded by the National Natural Science Foundation of China (NSFC), grant number 71771085 .

Acknowledgments: The authors would like to thank the editor of this journal and the reviewers for their detailed and helpful comments.

Conflicts of Interest: The authors declare no conflict of interest. 


\section{Nomenclature}

\begin{tabular}{|c|c|}
\hline$\rho$ & the conversion efficiency of energy storage \\
\hline$E_{r}$ & the released energy of energy storage \\
\hline$E_{S}$ & the stored energy of energy storage \\
\hline$E_{\text {total }}$ & the total required energy of an energy Internet system \\
\hline$E_{\text {basic }}$ & the demand of fixed basic energy \\
\hline$y$ & the total number of energy storage \\
\hline$e_{i}$ & the basic requirement for each energy storage \\
\hline$l$ & the number of energy storage in energy Internet \\
\hline$x_{i}$ & the stored energy of each energy storage \\
\hline$E_{\text {real }}$ & the required energy for real-time \\
\hline$E_{\text {non-real }}$ & the required energy for non-real-time \\
\hline C & the total cost \\
\hline$C_{i m i n}$ & the minimum value of the $i$ th energy storage cost \\
\hline$C_{\text {imax }}$ & the maximum value of the $i$ th energy storage cost \\
\hline f & the selection of cost according to actual situation \\
\hline E & the total stored energy of all energy storages in EI system \\
\hline$E_{R E}$ & the energy released by various energy networks \\
\hline$E_{S E}$ & the energy stored by energy storages \\
\hline$E_{C E}$ & the consumed energy \\
\hline$X_{\text {imax }}$ & the maximum storage capacity of each energy storage \\
\hline$\rho_{i}$ & the energy conversion efficiency of the $i$ th energy storage \\
\hline$n$ & the number of particles \\
\hline j & the $j$ th particle in PSO \\
\hline$d$ & the dimension of search space \\
\hline$t$ & the number of iterations \\
\hline$v_{t}$ & the velocity at the $t$ th iteration \\
\hline$q_{t}$ & the position at the $t$ th iteration \\
\hline$w$ & the inertia weight \\
\hline$c_{1}, c_{2}$ & the acceleration constants \\
\hline$r_{1}, r_{2}$ & the random values in the range $[0,1]$ \\
\hline$p_{\text {best }}$ & the best previous position of a particle \\
\hline$g_{\text {best }}$ & the value of the best particle among all the particles \\
\hline$\alpha$ & an agent in MAPSO \\
\hline$(a, b)$ & $\begin{array}{l}\text { the specific location of an Agent in the global environment, and } \mathrm{a}, \mathrm{b} \text { are the global } \\
\text { environment boundaries of MAPSO }\end{array}$ \\
\hline$A_{m, n}$ & the agent with position $(m, n)$ \\
\hline$N_{m, n}$ & the local environment of $A_{m, n}$ \\
\hline$M_{m, n}$ & the agent with the minimum fitness value among 8 neighbors of $A_{m, n}$ \\
\hline $\operatorname{rand}(-1,1)$ & a random number in the range $[-1,1]$ \\
\hline$\gamma$ & the united objective function \\
\hline$\vartheta_{c}$ & weight coefficients of objective function $C$ \\
\hline$\vartheta_{e}$ & weight coefficients of objective function $E$ \\
\hline
\end{tabular}




\section{Appendix}

Table A1. The list of classified literature.

\begin{tabular}{llll}
\hline \multicolumn{1}{c}{ Section } & \multicolumn{1}{c}{ Content } & \multicolumn{1}{c}{ References } & \multicolumn{1}{c}{ Country of Authors } \\
\hline \multirow{4}{*}{ Application of ES in EI } & \multicolumn{1}{c}{ The functions of ES in EI } & {$[10]$} & China \\
\cline { 2 - 4 } & The application of certain ES technology in EI & {$[11,12]$} & China \\
\cline { 2 - 4 } & The basic application of ES in EI & {$[14]$} & Qatar \\
\cline { 2 - 4 } & $\begin{array}{l}\text { The application and optimization of ES in } \\
\text { smart grid or hybrid energy systems }\end{array}$ & {$[13,15-18]$} & $\begin{array}{l}\text { Italy, Spain, USA, Turkey, } \\
\text { Singapore, Australia }\end{array}$ \\
\hline \multirow{3}{*}{$\begin{array}{l}\text { Coordination of ESs or ES } \\
\text { with renewable energies }\end{array}$} & Cooperation of various ESs & {$[19-24]$} & $\begin{array}{l}\text { Australia, China, Denmark, } \\
\text { Portugal, USA }\end{array}$ \\
\cline { 2 - 4 } & Coordination of ES and renewable energies. & {$[25-36]$} & $\begin{array}{l}\text { China, Italy, Portugal, Korea, } \\
\text { Iran, Brazil, Spain, Thailand, }\end{array}$ \\
\cline { 2 - 4 } & Coordination of ES and flexible demand & {$[37,38]$} & Japan, South Korea \\
\hline \multirow{3}{*}{ The application of MAPSO } & Reactive power optimization & {$[44]$} & China \\
\cline { 2 - 4 } & Distribution network reconfiguration & {$[45]$} & China \\
\cline { 2 - 4 } & Economic load dispatch & {$[46]$} & India \\
\cline { 2 - 4 } & Maximizing loadability limit of power systems & {$[47]$} & India \\
\hline
\end{tabular}

\section{References}

1. Abe, R.; Taoka, H.; McQuilkin, D. Digital grid: Communicative electrical grids of the future. IEEE Trans. Smart Grid 2011, 2, 399-410. [CrossRef]

2. Reka, S.S.; Dragicevic, T. Future effectual role of energy delivery: A comprehensive review of Internet of Things and smart grid. Renew. Sustain. Energy Rev. 2018, 91, 90-108. [CrossRef]

3. Huang, A.Q.; Crow, M.L.; Heydt, G.T.; Zheng, J.P.; Dale, S.J. The future renewable electric energy delivery and management (FREEDM) system: The energy Internet. Proc. IEEE 2011, 99, 133-148. [CrossRef]

4. Moghaddam, M.H.Y.; Leon-Garcia, A. A fog-based Internet of energy architecture for transactive energy management systems. IEEE Internet Things J. 2018, 5, 1055-1068. [CrossRef]

5. Tsoukalas, L.H.; Gao, R. From smart grids to an energy internet: Assumptions, architectures and requirements. Smart Grid Renew. Energy 2008, 1, 94-98.

6. Rifkin, J. The Third Industrial Revolution: How Lateral Power Is Transforming Energy, the Economy, and the World, 1st ed.; Palgrave Macmillan: New York, NY, USA, 2011; pp. 1-5, ISBN 0230115217.

7. Kalyanaraman, S. Back to the future: Lessons for Internet of energy networks. IEEE Internet Comput. 2016, 20, 60-65. [CrossRef]

8. Rajasekharan, J.; Koivunen, V. Optimal energy consumption model for smart grid households with energy storage. IEEE J. Sel. Top. Signal. Process. 2014, 8, 1154-1166. [CrossRef]

9. Wu, K.H.; Zhou, H. A multi-agent-based energy-coordination control system for grid-connected large-scale wind-photovoltaic energy storage power-generation units. Sol. Energy 2014, 107, 245-259. [CrossRef]

10. Zhu, Y.Q.; Hao, J.C.; Zhao, N.; Wang, X. Demands, functions and action manners of energy storage in Energy Internet. Adv. Technol. Electr. Eng. Energy 2018, 37, 68-75. (In Chinese)

11. Li, R.; Chen, L.J.; Yuan, T.J.; Li, C.L. Optimal dispatch of zero-carbon-emission micro Energy Internet integrated with non-supplementary fired compressed air energy storage system. J. Mod. Power Syst. Clean Energy 2016, 4, 566-580. [CrossRef]

12. Shen, Y.; Yao, W.; Fang, J.K.; Wen, J.Y. Liquid hydrogen with SMES and its application in Energy Internet. Power Syst. Technol. 2016, 40, 172-179. (In Chinese)

13. Baronti, F.; Vazquez, S.; Chow, M. Modeling, control, and integration of energy storage systems in e-transportation and smart grid. IEEE Trans. Ind. Electron. 2018, 65, 6548-6551. [CrossRef]

14. Mumtaz, F.; Bayram, I.S.; Elrayyah, A. Importance of energy storage system in the Smart Grid. Commun. Control Secur. Smart Grid 2017, 247-283. [CrossRef] 
15. Aktas, A.; Erhan, K.; Ozdemir, S.; Ozdemir, E. Experimental investigation of a new smart energy management algorithm for a hybrid energy storage system in smart grid applications. Electr. Power Syst. Res. 2017, 144, 185-196. [CrossRef]

16. Rahbar, K.; Vedady Moghadam, M.R.; Panda, S.K.; Reindl, T. Shared energy storage management for renewable energy integration in smart grid. arXiv 2016, 5, 1-5.

17. Sutanto, D. Electronic controlled energy storage devices and applications in future smart grid. J. Electron. Sci. Technol. 2011, 9, 3-8.

18. Faccio, M.; Gamberi, M.; Bortolini, M.; Nedaei, M. State-of-art review of the optimization methods to design the configuration of hybrid renewable energy systems (HRESs). Front. Energy 2018, 1, 1-32. [CrossRef]

19. Mokhtari, G.; Nourbakhsh, G.; Ghosh, A. Smart coordination of energy storage units (ESUs) for voltage and loading management in distribution networks. IEEE Trans. Power Syst. 2013, 28, 4812-4820. [CrossRef]

20. Wang, L.; Liang, D.H.; Crossland, A.F.; Taylor, P.C.; Jones, D.; Wade, N.S. Coordination of multiple energy storage units in a low-voltage distribution network. IEEE Trans. Smart Grid 2015, 6, 2906-2918. [CrossRef]

21. Mokhtari, G.; Nourbakhsh, G.; Anvari-Moghadam, A.; Ghasemi, N.; Saberian, A. Optimal cooperative management of energy storage systems to deal with over- and under-voltages. Energies 2017, 10, 293. [CrossRef]

22. Miranda, I.; Leite, H.; Silva, N. Coordination of multifunctional distributed energy storage systems in distribution networks. IET Gener. Transm. Distrib. 2016, 10, 726-735. [CrossRef]

23. Rostami, M.; Lotfifard, S. Scalable coordinated control of energy storage systems for enhancing power system angle stability. IEEE Trans. Sustain. Energy 2018, 9, 763-770. [CrossRef]

24. Zhu, Y.Q.; Zhao, N.; Wang, F.Y.; Wang, X. Coordination of various energy storage in Energy Internet. Adv. Technol. Electr. Eng. Energy 2018, 37, 10-16. (In Chinese)

25. Lee, T.Y.; Chen, N. The effect of pumped storage and battery energy storage systems on hydrothermal generation coordination. IEEE Trans. Energy Convers. 1992, 7, 631-637. [CrossRef]

26. Bortolini, M.; Gamberi, M.; Graziani, A. Technical and economic design of photovoltaic and battery energy storage system. Energy Convers. Manag. 2014, 86, 81-92. [CrossRef]

27. Bortolini, M.; Gamberi, M.; Graziani, A.; Pilati, F. Economic and environmental bi-objective design of an off-grid photovoltaic-battery-diesel generator hybrid energy system. Energy Convers. Manag. 2015, 106, 1024-1038. [CrossRef]

28. Sharma, U.C.; Prasad, R.; Sivakumar, S. Dynamic Cost Model for the Energy Mix Planning and the Electrical Grid Management; Sharma, U.C.; Prasad, R.; Sivakumar, S. Studium Press LLC: Houston, TX, USA, 2015; pp. 95-132.

29. Barros, J.A.; Leite, H. Coordinating independent non-dispatchable generation and energy storage systems. Int. J. Electr. Power Energy Syst. 2014, 62, 212-220. [CrossRef]

30. Kim, C.; Muljadi, E.; Chung, C.C. Coordinated control of wind turbine and energy storage system for reducing wind power fluctuation. Energies 2018, 11, 18-52.

31. Bakhtiari, H.; Naghizadeh, R.A. Multi-criteria optimal sizing of hybrid renewable energy systems including wind, photovoltaic, battery, and hydrogen storage with epsilon-constraint method. IET Renew. Power Gener. 2018, 12, 883-892. [CrossRef]

32. Khosravi, A.; Koury, R.N.N.; Machado, L.; Pabon, J.J.G. Energy, exergy and economic analysis of a hybrid renewable energy with hydrogen storage system. Energy 2018, 148, 1087-1102. [CrossRef]

33. Garcia-Trivino, P.; Fernandez-Ramirez, L.M.; Gil-Mena, A.J.; Llorens-Iborra, F.; Garcia-Vazquez, C.A.; Jurado, F. Optimized operation combining costs, efficiency and lifetime of a hybrid renewable energy system with energy storage by battery and hydrogen in grid-connected applications. Int. J. Hydrog. Energy 2016, 41, 23132-23144. [CrossRef]

34. Tephiruk, N.; Kanokbannakorn, W.; Kerdphol, T.; Mitani, Y.; Hongesombut, K. Fuzzy logic control of a battery energy storage system for stability improvement in an Islanded microgrid. Sustainability 2018, 10, 1645. [CrossRef]

35. Kang, B.; Jang, K.; Park, S.; Choi, M.; Park, S. Energy storage system control algorithm by operating target power to improve energy sustainability of smart home. Sustainability 2018, 10, 236. [CrossRef]

36. Mo, J.Y.; Jeon, W. How does energy storage increase the efficiency of an electricity market with integrated wind and solar power generation?-A case study of Korea. Sustainability 2017, 9, 1797. [CrossRef] 
37. Papadaskalopoulos, D.; Pudjianto, D.; Strbac, G. Decentralized coordination of microgrids with flexible demand and energy storage. IEEE Trans. Sustain. Energy 2014, 5, 1406-1414. [CrossRef]

38. Ghasemi, A.; Enayatzare, M. Optimal energy management of a renewable-based isolated microgrid with pumped-storage unit and demand response. Renew. Energy 2018, 123, 460-474. [CrossRef]

39. Kennedy, J.; Eberhart, R. Particle Swarm Optimization. In Proceedings of the ICNN'95-International Conference on Neural Networks, Perth, WA, Australia, 27 November-1 December 1995; IEEE: Piscataway, NJ, USA, 1995; pp. 1942-1948.

40. Abdessameud, A.; Tayebi, A. Distributed output regulation of heterogeneous linear multi-agent systems with communication constraints. Automatica 2018, 91, 152-158. [CrossRef]

41. Zurita, N.F.S.; Colby, M.K.; Tumer, I.Y.; Hoyle, C.; Tumer, K. Design of complex engineered systems using multi-agent coordination. J. Comput. Inf. Sci. Eng. 2018, 18, 011003. [CrossRef]

42. Kim, D.H.; Seiichi, S. Modified particle swarm algorithm for decentralized swarm agents. In Proceedings of the 2004 IEEE International Conference on Robotics and Biomimetics, Shenyang, China, 22-26 August 2005; IEEE: Piscataway, NJ, USA, 2005.

43. Kim, D.H.; Shin, S. Self-organization of decentralized swarm agents based on modified particle swarm algorithm. J. Intell. Rob. Syst. Theory Appl. 2006, 46, 129-149. [CrossRef]

44. Zhao, B.; Guo, C.X.; Cao, Y.J. A multi-agent based Particle Swarm Optimization approach for optimal reactive power dispatch. IEEE Trans. Power Syst. 2005, 20, 1070-1078. [CrossRef]

45. Xiao, K.; Huang, Z.X. Application of multi-agent Particle Swarm algorithm in distribution network reconfiguration. Comput. Eng. Appl. 2010, 46, 221-224. (In Chinese)

46. Kumar, R.; Sharma, D.; Sadu, A. A hybrid multi-agent based particle swarm optimization algorithm for economic power dispatch. Int. J. Electr. Power Energy Syst. 2011, 33, 115-123. [CrossRef]

47. Shunmugalatha, A.; Slochanal, S.M.R. Maximum loadability limit of a power system using multiagent-based hybrid particle swarm optimization. Electr. Power Compon. Syst. 2008, 36, 575-586. [CrossRef]

48. Diaz-Gonzalez, F.; Sumper, A.; Gomis-Bellmunt, O.; Villafafila-Robles, R. A review of energy storage technologies for wind power applications. Renew. Sustain. Energy Rev. 2012, 16, 2154-2171. [CrossRef]

49. Hadjipaschalis, I.; Poullikkas, A.; Efthimiou, V. Overview of current and future energy storage technologies for electric power applications. Renew. Sustain. Energy Rev. 2009, 13, 1513-1522. [CrossRef]

50. Luo, X.; Wang, J.H.; Dooner, M.; Clarke, J. Overview of current development in electrical energy storage technologies and the application potential in power system operation. Appl. Energy 2015, 137, 511-536. [CrossRef]

51. Wu, J.; Xing, X.W.; Liu, X.T.; Guerrero, J.M.; Chen, Z.H. Energy management strategy for grid-tied microgrids considering the energy storage efficiency. IEEE Trans. Ind. Electron. 2018, 65, 9539-9549. [CrossRef]

52. Pali, B.S.; Vadhera, S. A novel pumped hydro-energy storage scheme with wind energy for power generation at constant voltage in rural areas. Renew. Energy 2018, 127, 802-810. [CrossRef]

53. Amiryar, M.E.; Pullen, K.R.; Nankoo, D. Development of a high-fidelity model for an electrically driven energy storage flywheel suitable for small scale residential applications. Appl. Sci. 2018, 8, 453. [CrossRef]

54. Bak, Y.; Lee, J.S.; Lee, K.B. Low-voltage ride-through control strategy for a grid-connected energy storage system. Appl. Sci. 2018, 8, 57. [CrossRef]

55. Hammami, M.; Torretti, S.; Grimaccia, F.; Grandi, G. Thermal and performance analysis of a photovoltaic module with an integrated energy storage system. Appl. Sci. 2018, 7, 1107. [CrossRef]

56. Nourai, A. Large-scale electricity storage technologies for energy management. In Proceedings of the IEEE PES Summer Meeting, Chicago, IL, USA, 21-25 July 2002; IEEE: Piscataway, NJ, USA, 2002; pp. 310-315.

57. Liu, J.C.; He, D.D.; Long, T. Research on data integration of wind power to meet energy internet demand. Power Syst. Technol. 2017, 41, 978-984. (In Chinese)

58. Ter-Gazarian, A.G. Energy Storage for Power Systems, 2nd ed.; Institution of Engineering and Technology: London, UK, 2011; pp. 40-41, ISBN 9781849192194.

59. Xie, C.P.; Hong, Y.; Ding, Y.L.; Li, Y.L.; Radcliffe, J. An economic feasibility assessment of decoupled energy storage in the UK: With liquid air energy storage as a case study. Appl. Energy 2018, 225, 244-257. [CrossRef]

60. Eberhart, R.C.; Shi, Y. Comparing inertia weights and constriction factors in particle swarm optimization. In Proceedings of the 2000 Congress on Evolutionary Computation (CEC 2000), 16-19 July 2000; IEEE Computer Society: Washington,DC, USA, 2000; pp. 84-88. 
61. Jacques, F. Multi-Agent System: An Introduction to Distributed Artificial Intelligence; Addison-Wesley Professional: Boston, MA, USA, 1999; pp. 12-21, ISBN 0201360489.

62. Wooldridge, M.J. An Introduction to Multi-Agent Systems; John Wiley \& Sons: Hoboken, NJ, USA, 2009; Volume 4, pp. 125-128.

63. Kumar, R.; Sharma, D. A new hybrid multi-agent-based particle swarm optimisation technique. Int. J. Bio-Insp. Comput. 2009, 1, 259-269. [CrossRef]

64. Kannan, S.M.; Renuga, P.; Kalyani, S.; Muthukumaran, E. Optimal capacitor placement and sizing using Fuzzy-DE and Fuzzy-MAPSO methods. Appl. Soft Comput. 2011, 11, 4997-5005. [CrossRef]

65. Yang, H.T.; Tzeng, Y.T.; Tsai, M.S. Loss-minimized distribution system reconfiguration by using improved multi-agent based particle swarm optimization. In Proceedings of the Asia-Pacific Power and Energy Engineering Conference (APPEEC 2010), Chengdu, China, 28-31 March 2010; IEEE: Piscataway, NJ, USA, 2010.

66. Roshanzamir, M.; Balafar, M.A.; Razavi, S.N. Empowering particle swarm optimization algorithm using multi agents' capability: A holonic approach. Knowl. Based Syst. 2017, 136, 58-74. [CrossRef]

67. Gao, F. Super Learning Manual of Intelligent Algorithm of MATLAB, 1st ed.; Posts \& Telecom Press: Beijing, China, 2014; pp. 254-258, ISBN 978-7-115-34879-1.

68. Zhang, L.H.; Xin, H.; Wu, J.; Ju, L.W.; Tan, Z.F. A multiobjective robust scheduling optimization mode for multienergy hybrid system integrated by wind power, solar photovoltaic power, and pumped storage power. Math. Prob. Eng. 2017, 2017, 9485127. [CrossRef]

(C) 2018 by the authors. Licensee MDPI, Basel, Switzerland. This article is an open access article distributed under the terms and conditions of the Creative Commons Attribution (CC BY) license (http://creativecommons.org/licenses/by/4.0/). 